Abstract-Temperature data received post mortem in 2008-13 from 15 of 36 juvenile Steller sea lions (Eumetopias jubatus) that had been surgically implanted in 2005-11 with dual life history transmitters (LHX tags) indicated that all 15 animals died by predation. In 3 of those 15 cases, at least 1 of the 2 LHX tags was ingested by a cold-blooded predator, and those tags recorded, immediately after the sea lion's death, temperatures that corresponded to deepwater values. These tags were regurgitated or passed 5-11 days later by predators. Once they sensed light and air, the tags commenced transmissions as they floated at the ocean surface, reporting temperatures that corresponded to regional sea-surface estimates. The circumstances related to the tag in a fourth case were ambiguous. In the remaining 11 cases, tags sensed light and air immediately after the sea lion's death and reported temperatures that corresponded to estimates of regional sea-surface temperatures. In these 11 cases, circumstances did not allow for inferences on the species of predator. Among reported poikilotherm predators of Steller sea lions, only the Pacific sleeper shark (Somniosus pacificus) is known to have body core temperatures that are near ambient. The data from this study indicate that Pacific sleeper sharks need to be considered as a possible source of mortality of juvenile Steller sea lions in the region of the Gulf of Alaska.

Manuscript submitted 19 June 2013. Manuscript accepted 21 August 2014. Fish. Bull. 112:297-310 (2014). doi:10.7755/FB.112.4.6

The views and opinions expressed or implied in this article are those of the author (or authors) and do not necessarily reflect the position of the National Marine Fisheries Service, NOAA.

\section{In cold blood: evidence of Pacific sleeper shark (Somniosus pacificus) predation on Steller sea lions (Eumetopias jubatus) in the Gulf of Alaska}

\author{
Markus Horning (contact author) ${ }^{1,2}$ \\ Jo-Ann E. Mellish ${ }^{3,4}$ \\ Email address for contact author: markus.horning@oregonstate.edu \\ ${ }^{1}$ Department of Fisheries and Wildlife and \\ Marine Mammal Institute \\ College of Agricultural Sciences \\ Oregon State University \\ 2030 SE Marine Science Drive \\ Newport, Oregon 97365 \\ 2 Coastal Oregon Marine Experiment Station \\ Oregon State University \\ 2030 SE Marine Science Drive \\ Newport, Oregon 97365 \\ 3 Alaska Sea Life Center \\ P.O. Box 1329 \\ Seward, Alaska 99664 \\ ${ }^{4}$ School of Fisheries and Ocean Sciences \\ University of Alaska Fairbanks \\ P.O. Box 757220 \\ Fairbanks, Alaska 99755-7220
}

The western distinct population segment (WDPS) of the Steller sea lion (Eumetopias jubatus) (west of $144^{\circ} \mathrm{W}$ ) has declined to approximately $20 \%$ of the levels encountered before 1975 (National Research Council, 2003), and declines were at or above $5 \%$ per year in some areas. Recent data indicate trends of slightly increasing population overall and continuing steep declines for the western Aleutian Islands from 2000 to 2012 (Fritz et al., 2013). Limited trend data indicate stable or slightly increasing levels for the Prince William Sound-Kenai Fjords area of the Gulf of Alaska (Fritz et al., 2013).

Multiple factors have been posited as driving past and present population trends of the Steller sea lion (National Research Council, 2003). York (1994) hypothesized reduced juvenile survival in the Gulf of Alaska region during the height of the decline. Holmes et al. (2007) hypothesized that juvenile survival rates for the period of 1997-2004 in the same region had recovered but that birth rate had steadily declined. Specific proximate drivers of the hypothesized reduced juvenile survival or reduced birth rates remain unknown. Suggested causes include nutritional stress through competition with com- mercial fisheries (National Research Council, 2003), the "inadequate food/ocean climate hypothesis" (e.g., Trites et al., 2007), and the "predation hypothesis" (e.g., Williams et al., 2004). However, to date no direct test of any of these hypotheses has been published in peer-reviewed literature for any region of the WDPS.

Direct observations (Ford et al., 1998; Maniscalco et al., 2007), physical evidence (Heise et al., 2003), and telemetered data (Horning and Mellish, 2009, 2012) reveal the occurrence of predation on Steller sea lions. From a review of research conducted through the 1990s, the National Research Council (2003) concluded that the recovery of the WDPS was more likely limited by predation than by resource-driven effects. Reported predators of Steller sea lions include not only the transient ecotype of the killer whale (Orcinus orca) (Ford et al., 1998) but also the white shark (Carcharodon carcharias), the salmon shark (Lamna ditropis), and the Pacific sleeper shark (Somniosus pacificus) (Loughlin and York, 2000). However, the accurate detection and quantification of sea lion depredation at sea has been labeled as "empirically intractable" (Williams et al., 2004). 
To address this constraint, we specifically developed the life history transmitter (LHX tag; Wildlife Computers ${ }^{1}$, Redmond, WA; described in Horning and Hill, 2005 ) to detect and determine causes of Steller sea lion mortality irrespective of time and location of mortality, or age of host. LHX tags were designed to remain implanted through the entire life of the host (Horning et al., 2008). Surgical implantation allows multiyear monitoring beyond the annual molt that limits the use of externally attached devices. LHX tags do not transmit while inside the host body, greatly extending battery life beyond 10 years. Tags liberated from decomposing, dismembered, or digested bodies send transmissions to the Argos telemetry system (CLS America Inc., Lantham, MD) aboard NOAA satellites with global coverage (Soma and Tsutsumi, 1986). LHX tags, therefore, provide postmortem data on time and date, location, and causes of mortality with spatially and temporally unlimited resight effort (Horning and Mellish, 2009). Here, we provide indirect evidence (from LHX tag data) of predation by Pacific sleeper sharks on juvenile Steller sea lions.

\section{Materials and methods}

This study was carried out in strict compliance with all applicable animal care and use guidelines under the U.S. Animal Welfare Act and was approved as required under the U.S. Marine Mammal Protection Act and the U.S. Endangered Species Act by the National Marine Fisheries Service (permit numbers 1034-1685, 1034-1887, 881-1890, 881-1668, 14335, and 14336) and by the Institutional Animal Care and Use Committees of the Alaska Sea Life Center (permit numbers 02-015, 03-007, 05-002, 06-001, 08-005, and R10-09-04) and Texas A\&M University (permit numbers 2003-181, 2005-170, and 2006-37). All surgeries were performed under aseptic conditions and under full anesthesia administered by inhalant gas, and all efforts were completed in a way meant to minimize pain and suffering.

\section{Life history transmitters}

We used satellite-linked LHX tags (Horning and Hill, 2005) to determine survival rates and infer causes of mortality in juvenile Steller sea lions in the Gulf of Alaska. LHX tags are intraperitoneally implanted archival transmitters that monitor sensor data through the life of host animals. Select recorded data are transmitted (uplinked) post mortem to the Argos system aboard NOAA satellites, after the positively buoyant tags are liberated from a decomposing, dismembered, or digested carcass. LHX tags provide $48 \mathrm{~h}$ of temperature data across detected mortality events. In 30-min

\footnotetext{
${ }^{1}$ Mention of trade names or commercial companies is for identification purposes only and does not imply endorsement by the National Marine Fisheries Service, NOAA.
}

increments, 96 temperature values are recorded with an accuracy better than $0.1^{\circ} \mathrm{C}$ and with a nonlinear resolution from $0.2^{\circ} \mathrm{C}\left(\right.$ at $0^{\circ} \mathrm{C}$ ) to $0.25^{\circ} \mathrm{C}\left(\right.$ at $40^{\circ} \mathrm{C}$ ), for 48 ante mortem and 48 postmortem values. Mortality is detected when temperature drops below the preset threshold of $24^{\circ} \mathrm{C}$. In addition to a temperature sensor, LHX tags incorporate a radiometric irradiance sensor and a proprietary radio-frequency immersion sensor (see Horning and Hill, 2005) that allows the classification of the medium surrounding the antenna portion of a tag as tissue, saltwater, or air.

Tags begin to transmit after they sense surrounding air or sufficient ambient light. Thereafter, current temperature (hereafter, called uplink temperature) and irradiance are included in each transmission. Additional diagnostic sensor data transmitted by the tags allow the classification of ambient light conditions from time of death to onset of transmissions. Light conditions are classified into the categories of complete darkness or light exceeding a preset irradiance threshold of $2.9 \times 10^{-8} \mathrm{Wcm}^{-2}$ (for $\lambda=527-583 \mathrm{~nm}$ ). This threshold corresponds with the approximate penetration depth of radiant energy in the ocean that ranges from $0 \mathrm{~m}$ for a starlit night to $25 \mathrm{~m}$ for a night with a full moon, 100 $\mathrm{m}$ for a dark, cloudy day, and $200 \mathrm{~m}$ for a bright day, as estimated from the optical properties of seawater reported for the Alaska Gyre (Sasaki et al., 2001). Tags perform a daily test of the irradiance sensor through a built-in LED light source, and any faults are reported. For short-term diagnostic monitoring of postoperative recovery, LHX tags were programmed to transmit tag temperatures every 15-60 min for periods ranging up to 1-2 weeks after implantation. When the animals were not submerged in the saltwater pools of the recovery facility, these data were received with a nearby $(<20 \mathrm{~m})$ handheld uplink receiver.

The Argos system provides approximate locations of uplinking tags with accuracy indicated within a range from $0.49 \mathrm{~km}$ to $4.18 \mathrm{~km}$ (Soma and Tsutsumi, 1986; Costa et al., 2010). However, LHX tags commence transmissions after extrusion only at local noon. This timing may result in the estimates of the first position occurring up to $24 \mathrm{~h}$ post mortem for immediate extrusion events or after longer periods for delayed extrusions. We previously have estimated event location accuracy at approximately $10 \mathrm{~km}$ (Horning and Mellish, 2009).

\section{Inferring causa mortis from temperatures}

The temperature, irradiance, and immersion data allow the classification of detected mortality events as 1) death at sea by massive trauma likely due to predation or as 2) nonpredation death (Horning and Mellish, 2009). The normal abdominal temperature of healthy pinnipeds-although not well studied-is thought to range from $36^{\circ} \mathrm{C}$ to $38^{\circ} \mathrm{C}$ (Whittow, 1987). Antemortem temperature patterns may reveal hypothermia or pyrexia (fever), the former indicative of chronic energetic 


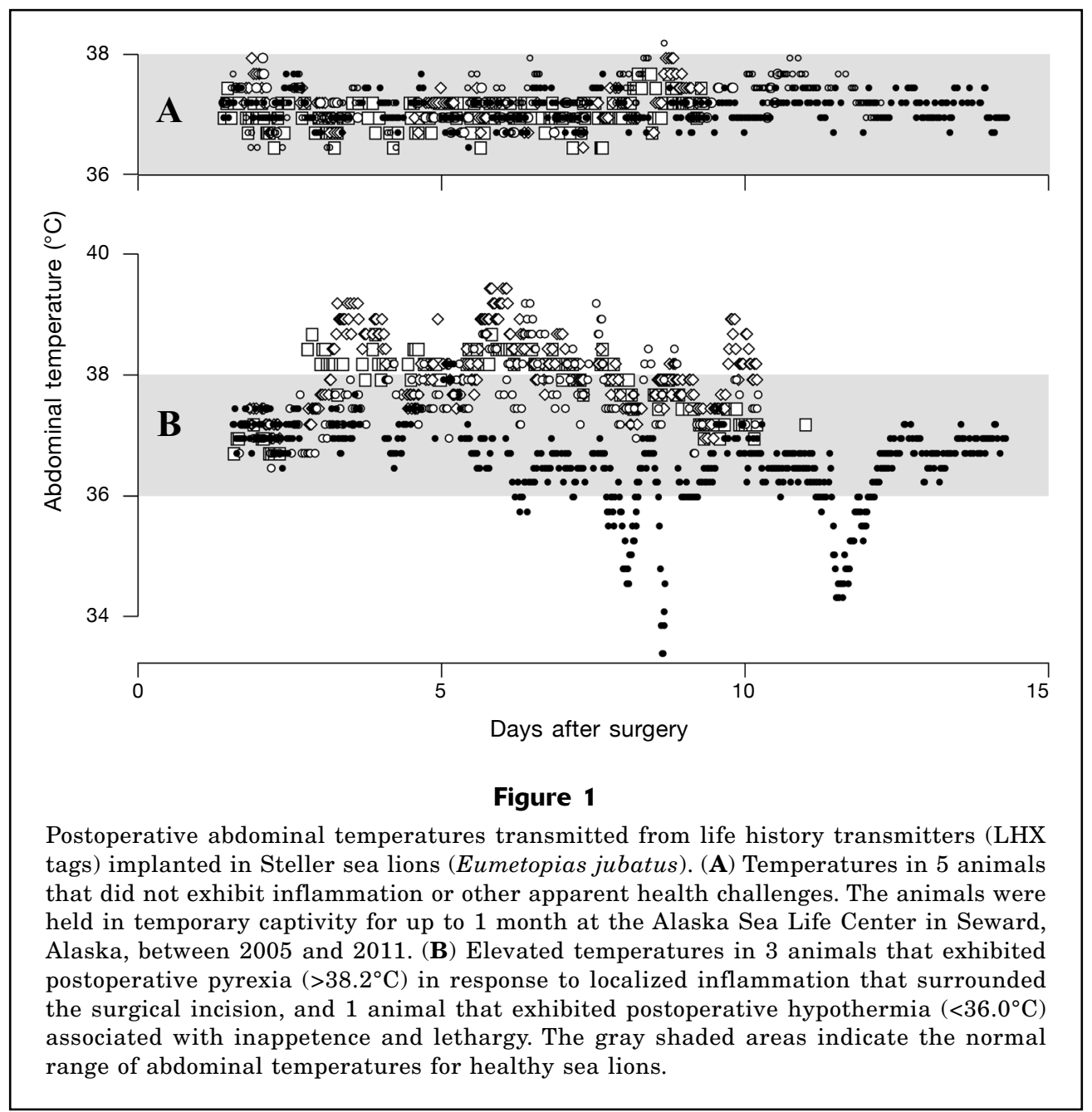

imbalance and starvation (Rosen et al., 2007), the latter indicative of inflammatory responses to immune challenges (Stoskopf, 2005).

During our postoperative monitoring of captive sea lions, most sea lions exhibited body core temperatures between $36.0^{\circ} \mathrm{C}$ and $38.2^{\circ} \mathrm{C}$ (Fig. 1A). However, several animals that were experiencing immunological challenges in the form of temporary, localized inflammations around the sutures at the incision site exhibited repeated abdominal temperatures above $38.2^{\circ} \mathrm{C}$ and up to $39.4^{\circ} \mathrm{C}$ for multiple days (Fig. 1B). Inflammation was evident in the form of visible discharge accompanied with localized swelling and localized elevation of surface temperatures determined with infrared thermography. One animal that was experiencing depressed appetence and lethargy exhibited reduced abdominal temperatures repeatedly over several days (Fig. 1B). The temperatures of all animals returned within the normal range of $36.0-38.2^{\circ} \mathrm{C}$ before their release. Exertion hyperthermia may temporarily elevate temperatures to $39^{\circ} \mathrm{C}$, but such events are limited to $<1 \mathrm{~h}$. Therefore, sustained (longer than several hours) ante- mortem temperatures outside of the range from $36^{\circ} \mathrm{C}$ to $38^{\circ} \mathrm{C}$ range should be indicative of compromised health conditions, such as starvation or disease.

Immediately after the death of warm-blooded animals, intact bodies will gradually cool over a period of several hours at rates proportional to initial body temperature and mass, insulation, and type, temperature, and flow rate of the surrounding medium (Marshall and Hoare, 1962). Models of algor mortis (postmortem cooling) have been applied in human forensic pathology to estimate time of death when body mass is known (Henssge, 1995). When time of death and cooling rates are known, the same models can be solved for mass. We previously have parameterized an algor mortis model for sea lions (Horning and Mellish, 2009). This sea lion model reasonably predicts cooling of sea lion carcasses in air and water (Fig. 2, D and E) and allows for estimation of mass at time of death. If implanted LHX tags remain embedded in intact bodies after death, then they should record gradual cooling while in darkness and surrounded by tissue. Such temperature data should produce cooling curves similar to those shown in 


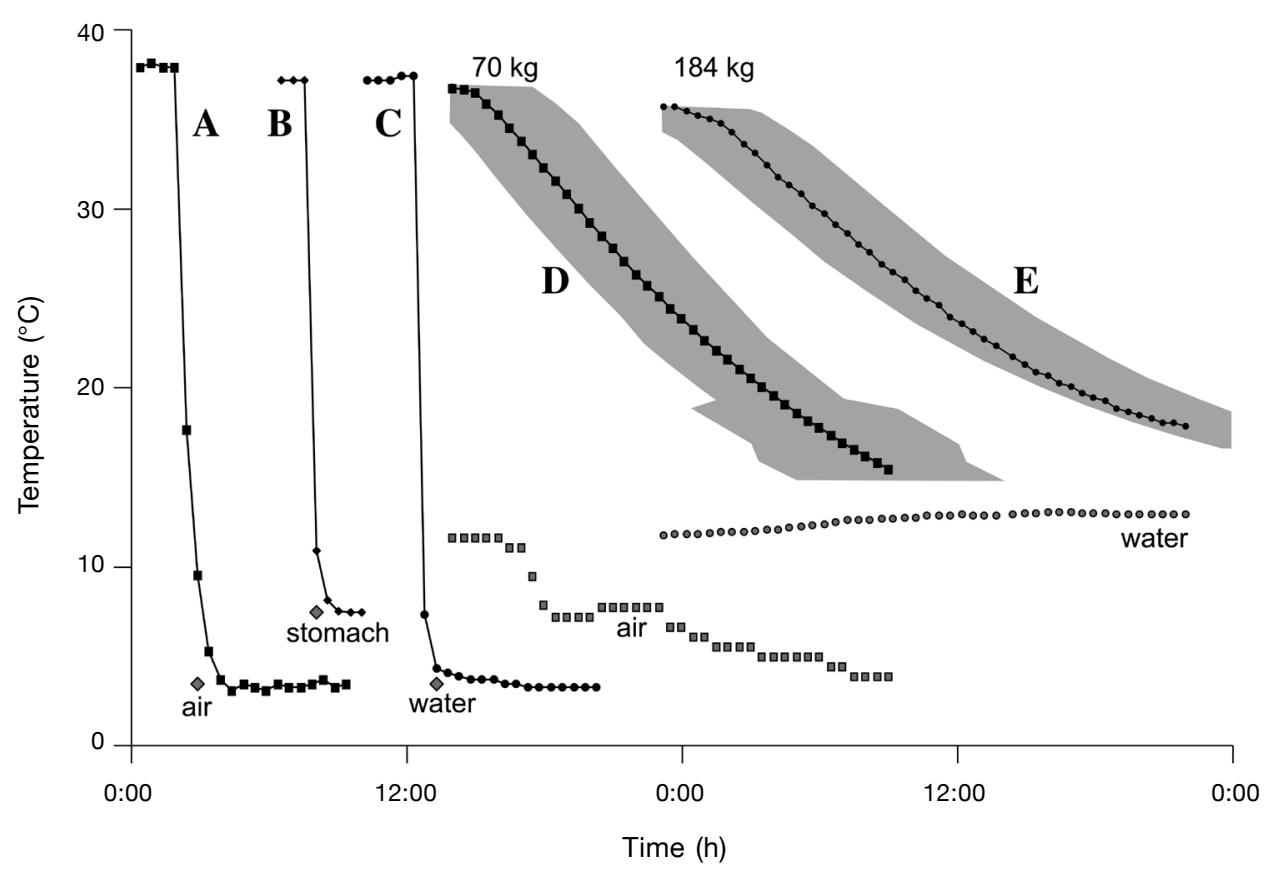

Figure 2

Temperatures recorded by life history transmitters (LHX tags) during different cooling experiments in the laboratory. Temperatures were recorded in 30-min increments by LHX tags equilibrated at approximately $36-38^{\circ} \mathrm{C}$ and subsequently transferred to different media, such as air, water, and stomach tissue. Temperatures of the transfer media are indicated by gray symbols. (A) LHX tag transfer from water bath to air at $3.5^{\circ} \mathrm{C}$. (B) LHX tag transfer from water bath into gastric tissue at $7.5^{\circ} \mathrm{C}$. (C) LHX tag transfer from water bath into water at $3.5^{\circ} \mathrm{C}$. (D) LHX tag abdominally implanted into a 70-kg California sea lion (Zalophus californianus) immediately post mortem at the Alaska Sea Life Center in Seward, Alaska, and the carcass then cooling in ambient air at $4-12^{\circ} \mathrm{C}$ (gray squares). (E) LHX tag abdominally implanted into a 184-kg California sea lion at The Marine Mammal Center in Sausalito, California, immediately post mortem, and the carcass cooling in ambient water at $12-13^{\circ} \mathrm{C}$ (gray circles). Shaded areas for D, E represent ranges of 95\% confidence intervals from the outputs of the algor mortis model (for details, see the Materials and methods section). Measurements shown for A, B, and C were data collected during laboratory experiments conducted at Oregon State University in Newport, Oregon, in 2005. The sea lion carcasses were made available by regional stranding networks in Alaska (2008) and California (2007). The sea lions were euthanized before insertion of LHX tags for reasons unrelated to this project.

Figure 2, D and E. Tags that remain embedded in parts of dismembered bodies also should record temperatures that indicate gradual cooling but at rates considerably faster than the cooling rates for intact bodies (Horning and Mellish, 2009). Alternatively, the temperatures of tags that are fully liberated from dismembered bodies should quickly adjust to temperatures of the surrounding medium, as illustrated in Figure 2, A-C.

The above listed considerations indicate 4 possible causae mortis scenarios (see Horning and Mellish, 2009).

Type I: Very rapid drops in postmortem temperature (as shown in Figure 2, A and C) that are associated with immediate sensing of ambient light or air must be the result of direct tag extrusion. Such a sequence of events, when combined with the immediate onset of transmissions, indicates traumatic death by dismemberment leading to immediate tag extrusion, most likely due to predation. A type-I scenario also could be caused by scavenging if this process releases the tags from the body and if it occurred within $60 \mathrm{~min}$ of death (depending on the mass of the sea lion; otherwise, the onset of gradual cooling would be detectable). In this case, scavenging would have been preceded immediately by death due to other causes, and any deaths caused by disease or starvation additionally should be associated with antemortem temperatures outside of the normal range of $36.0-38.2^{\circ} \mathrm{C}$.

Type II: A gradual temperature drop with substantially delayed sensing of light or air and delayed onset 
of transmissions, as shown in Figure 2, D and E, indicates that the tag remained in the carcass as it cooled. This scenario suggests a nontraumatic death resulting from disease, starvation, or drowning due to entanglement. Events caused by disease or starvation additionally should be associated with antemortem temperatures outside of the normal range of $36.0-38.2^{\circ} \mathrm{C}$.

Type III: Gradual but quicker than predicted cooling with delayed sensing of light and air may indicate traumatic predator attacks and partial dismemberment even if tags remain embedded in tissue.

Type IV: Very rapid drops in postmortem temperatures, as shown in Figure 2B, without immediate sensing of light or air indicate dismemberment and tag ingestion by a cold-blooded predator. Ingestion by a warm-blooded predator would result in no discernible changes in temperature and light until expulsion from the predator's digestive tract. A type-IV scenario also could be caused by scavenging if it occurred and if the tags were ingested within 60 min post mortem (otherwise, the onset of gradual cooling would be detectable). In this case, scavenging would have been preceded immediately by death due to other causes. Any deaths caused by disease or starvation additionally should be associated with antemortem temperatures outside of the normal range of $36.0-38.2^{\circ} \mathrm{C}$.

\section{Tag deployments and controls}

We implanted LHX tags into 36 juvenile Steller sea lions captured in Prince William Sound, Alaska, from 2005 to 2011 (Horning and Mellish, 2012). Dual LHX tags were used in all but the first 2 animals to increase and determine probability of detection of a mortality event (the first 2 animals received only single implants). LHX tags were implanted intraperitoneally while the sea lions were under gas anesthesia and according to standard aseptic surgical techniques (Horning et al., 2008). All animals were released in Resurrection Bay in the Kenai Fjords region, at ages of 14-26 months and at a mean mass of $128.6 \mathrm{~kg}$ (standard deviation [SD] 28.6; range: $73-198 \mathrm{~kg}$ ). In addition to live animal deployments, we conducted 10 simulation tests by implanting dual LHX tags in sea lion carcasses obtained from regional stranding networks and subsequently deposited ashore $(n=5)$ or at sea $(n=5)$ in California and Oregon.

Previously published control studies with animals monitored during temporary captivity (21-71 d) and tracked for a mean postrelease period of $86 \mathrm{~d}$ (SD 55; range: $10-242 \mathrm{~d} ; n=35)$ for implanted animals and of $76 \mathrm{~d}$ (SD 54; range: $11-194 ; n=30$ ) for nonimplanted animals-with all animals having conventional satellite transmitters externally attached after their release (Wildlife Computers SDRT-16 and SPLASH-5 tags)confirmed that 1) implant surgery results in mild to moderate wound healing responses and temporary elevation of white cell counts and haptoglobin concentrations, with full physiological recovery within $45 \mathrm{~d}$ following surgery; 2) tags and surgery result in zero mortality to $45 \mathrm{~d}$; 3) postrelease foraging and ranging behavior does not differ between implanted and nonimplanted animals or between temporarily captive and free-ranging animals; and 4) the cumulative survival of animals over the ages of $14-60$ months was $0.415(95 \%$ confidence intervals $[\mathrm{CI}]=0.26-0.63)$, compared with $0.413(95 \%$ CI=0.27-0.55) for mark-resight studies based on hot iron branding conducted by the National Marine Fisheries Service, providing no evidence of any effects of LHX tags or implant surgery on survival to the age of 5 years (Mellish et al., 2006, 2007; Thomton et al., 2008; Petrauskas et al., 2008; Walker et al., 2009; Horning and Mellish, 2012).

\section{Received data and environmental data}

We estimated probability of event detection from the ratio of dual to single tag returns. We first estimated uplink failures (the combination of technical tag failures and transmissions from a functional tag that did not reach any satellite because of tag exposure constraints) as

$$
P_{\text {fail }}=C_{\text {single }} /\left(C_{\text {single }}+2 C_{\text {dual }}\right) \text {, }
$$

where $C_{\text {single }}=$ the count of single returns; and $C_{\text {dual }}=$ the count of dual returns.

Then, a correction factor $F$ was derived as $F=1 /$ (1$P_{\text {fail }}{ }^{2}$ ), and the corrected number of mortality events $E_{\text {corr }}$ was calculated as $E_{\text {corr }}=F\left(C_{\text {single }}+C_{\text {dual }}\right)$. From $P_{\text {fail }}$, the probability of event detection $P_{\text {detect }}$ in turn was derived as $P_{\text {detect }}=1-P_{\text {fail }}{ }^{2}=1 / F$. Ranges containing $95 \%$ of the likely variance for the estimate of $P_{\text {fail }}$ were derived from the cumulative distribution function of a Monte Carlo simulation ( $>2500$ iterations) of randomly assigned individual tag failures for $0<P_{\text {fail-simu- }}$ lated $<1$ yielding $P_{\text {fail }}$ not exceeding the observed value without increasing $E_{\text {corr }}$ integer counts. The range of 95\% CI for $P_{\text {fail }}$ in turn yielded confidence intervals for $F$ and $E_{\text {corr }}$.

Sea-surface temperature (SST) composite data derived from the NOAA Geostationary Operational Environmental Satellites (GOES) and Polar-orbiting Environmental Satellites (POES) were obtained for specific dates from the Comprehensive Large Arraydata Stewardship System (CLASS) (SST50 or SST100 products available from http://www.nsof.class.noaa.gov/ saa/products/welcome, accessed June 2013). In situ SST data for specific dates were obtained from NOAA's National Data Buoy Center (available from http://www. ndbc.noaa.gov/, accessed June 2013). Long-term averages of water column temperature profiles from 1970 to 2012 for the GAK1 location, at $59^{\circ} 50.7^{\prime} \mathrm{N}, 149^{\circ} 28.0^{\prime} \mathrm{W}$, near the Kenai Fjords region of the northern Gulf of Alaska were obtained from a time-series data set of the University of Alaska's Institute of Marine Science (available from http://www.ims.uaf.edu/gak1/, accessed June 2013). Temperature estimates for deeper waters 


\section{Table 1}

Animal and event details for 15 mortalities, for which complete data sets were available, detected in juvenile Steller sea lions (Eumetopias jubatus) in the Gulf of Alaska between 2005 and 2013. Two values within a cell represent data returns from dual life history transmitters (LHX tags) implanted in sea lions, and, in the case of single values, only data from one tag was received. Mass at death was predicted from mean growth rates for age class and sex (Winship et al. ${ }^{1}$ ) applied to mass at release. Postmortem temperature $(T)$ is the mean of values recorded from time of death for $24 \mathrm{~h}$ or to onset of data transmissions from tags. In cases for which a temperature range for $24 \mathrm{~h}$ post mortem is not provided, tags began transmissions in less than $24 \mathrm{~h} . \mathrm{SST}=$ sea-surface temperature.

\begin{tabular}{|c|c|c|c|c|c|c|c|c|c|c|c|c|c|c|c|}
\hline Animal no. & 52 & 57 & 51 & 44 & 54 & 63 & 35 & 64 & 46 & 47 & 58 & 59 & 32 & 33 & 62 \\
\hline Month of death & Aug & Sep & Oct & Nov & May & Dec & May & Dec & Jan & Jan & Feb & Jan & Feb & Feb & Mar \\
\hline Age at death $(y)$ & 4.1 & 2.3 & 1.4 & 2.4 & 1.9 & 1.5 & 1.9 & 1.5 & 2.6 & 1.6 & 1.7 & 2.6 & 1.7 & 1.7 & 2.7 \\
\hline Predicted mass at death (kg) & 243 & 137 & 110 & 161 & 96 & 121 & 163 & 130 & 171 & 110 & 116 & 152 & 158 & 144 & 148 \\
\hline & & 0.1 & 0.6 & 1 & & 1 & 0.4 & 5 & 0.4 & 0.1 & 1 & 0.2 & & 0.9 & 0.6 \\
\hline Days to transmit & 11 & 0.1 & 0.6 & 1 & 0.2 & 1 & 0.4 & 9 & 0.4 & 0.1 & 1 & 0.2 & 16 & 0.9 & 0.6 \\
\hline & & 10.4 & 9.81 & 8.58 & & 5.20 & 5.07 & 7.55 & 4.96 & 4.75 & 3.96 & 3.37 & & 3.27 & 3.60 \\
\hline$T$ post mortem $\left({ }^{\circ} \mathrm{C}\right)$ & 5.53 & 10.5 & 9.66 & 8.41 & 6.77 & 7.02 & 4.56 & 7.54 & 4.79 & 4.54 & 4.04 & 3.42 & 4.51 & 3.16 & 3.51 \\
\hline$T$ range $24 \mathrm{~h}$ post mortem $\left({ }^{\circ} \mathrm{C}\right)$ & 0.0 & - & - & $\begin{array}{l}2.2 \\
2.4\end{array}$ & - & $\begin{array}{l}1.8 \\
0.2\end{array}$ & - & $\begin{array}{l}0.0 \\
0.0\end{array}$ & - & - & $\begin{array}{l}1.4 \\
0.8\end{array}$ & - & & & \\
\hline Regional SST $\left({ }^{\circ} \mathrm{C}\right)$ & 11.6 & 10.6 & 9.6 & 8.2 & 6.9 & 5.1 & 5.0 & 5.0 & 4.9 & 4.7 & 4.0 & 3.7 & 3.7 & 3.4 & 4.1 \\
\hline SST source $^{2}$ & 3,7 & 4 & 3,6 & 4,11 & 3,6 & 8,13 & 3,9 & 8,13 & 3,10 & 3,5 & 4,8 & 7,13 & 12,13 & 13 & 6,13 \\
\hline
\end{tabular}

${ }^{1}$ Winship, A. J., A. W. Trites, and D. G. Calkins. 2001. Growth in body size of the Steller sea lion (Eumetopias jubatus). J. Mammal. 82:500-519.

${ }^{2}$ Values from multiple sources were averaged (see Materials and methods section): ${ }^{3}$ Comprehensive Large Array-data Stewardship System; NOAA Data Buoy No. or identifier: ${ }^{4} 46060,{ }^{5} 46061,646076,{ }^{7} 46080,{ }^{8} 46081,{ }^{9}$ NKTA2, ${ }^{10}$ SNDA2, and ${ }^{11}$ VDZA2; ${ }^{12}$ GAK1 station of the Institute of Marine Science, University of Alaska Fairbanks; ${ }^{13}$ first uplink from LHX tag.

in Prince William Sound were averaged from values reported for locations in the Whale Bay, Eaglek Bay, and Zaikof Bay by Gay and Vaughan (2001).

\section{Results}

We detected 17 mortality events between 22 November 2005 and 15 June 2013, over 40,620 cumulative exposure days in 36 implanted animals (28,202 days over the age range of $14-60$ months). All 17 events were from animals with dual implants. Thirteen events yielded dual returns, and 4 events yielded single returns. Therefore, from the 34 tags implanted in the 17 animals that died, we recovered 27 full and 3 partial data sets; 4 tags returned no data. We recovered 18 full data sets from 20 tags in 10 carcass simulations; 2 tags yielded no data. Tags from carcasses uplinked on average within 32 days of deposition (SD 14.2; range: $14-65 \mathrm{~d} ; n=18$ ). From the ratio of dual $(n=21)$ to single $(n=6)$ data returns from the 52 tags in 27 events, we estimated event detection probability at $98.4 \%(\mathrm{CI}=95.0-100.0)$. This result indicates that we most likely did not miss any occurrences of mortal- ity within our sample of 36 animals implanted with transmitters.

Of the 17 detected events, 2 yielded insufficient data to allow for inferences on causes of mortality. Complete temperature and diagnostic data sets from at least 1 tag per animal were produced from each of 15 events (Table 1). Antemortem temperatures in all of the 15 detected mortality events with data were within normal ranges for healthy animals $\left(36.0-38.2^{\circ} \mathrm{C}\right)$, and there as no evidence of pyrexia or hypothermia (Figs. 3-5). All of these 15 events occurred at sea and were classified as predation, as detailed later. The combined probability distribution of single to dual tag returns of $2+13$ for the 15 predation events and $2+8$ for the 10 carcass tests that constitute simulated nontraumatic deaths gave an odds ratio of 1.625 , indicating no differences in detection probabilities between predation events and simulated nontraumatic events (Fisher's exact probability test: $P_{(2,1)}=1.0$; Fisher, 1922).

Of the 15 detected predation events, 11 events fell into a type-I scenario. In these events, temperatures dropped precipitously, with a mean peak $\Delta T$ of $-0.81^{\circ} \mathrm{C}$ $\mathrm{min}^{-1}$ (SD 0.1), to ambient values that corresponded to estimates of regional SSTs (Fig. 3; Table 1). This rate of 


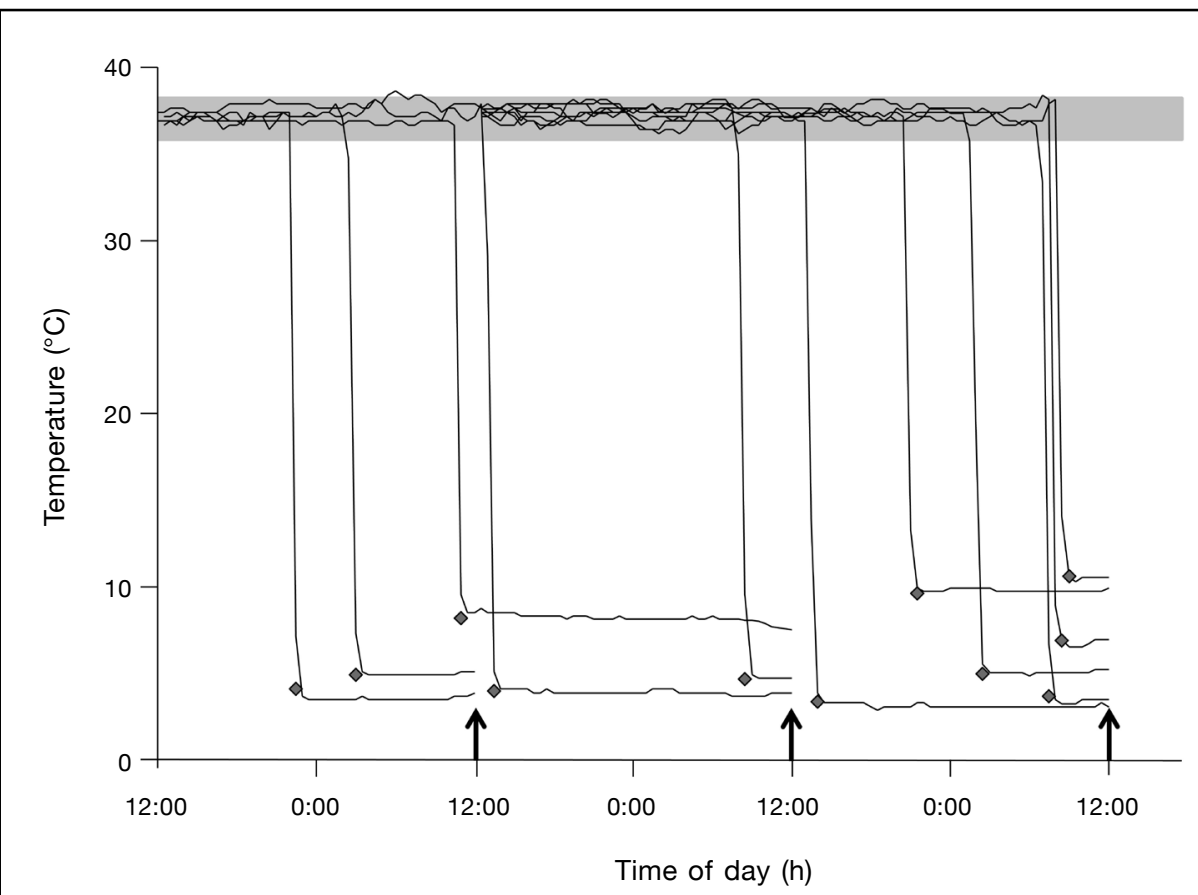

Figure 3

Antemortem and postmortem temperatures recorded by life history transmitters (LHX tags) for 11 mortality events detected in juvenile Steller sea lions (Eumetopias jubatus) with rapid onset of transmissions. Temperatures were recorded by LHX tags in 30-min increments and subsequently transmitted through the Argos satellite system. All events occurred in the Gulf of Alaska between 2008 and 2013 (for further details, see Table 1 and the Materials and methods section). Data from only one tag are shown for each animal. If data from both tags were available, then the data patterns from one tag that are not shown here did match the patterns of the other tag shown here. Because these 11 events occurred on different dates, data from one tag from each event were arbitrarily assigned to one of 3 sections of this graph solely for clarity. Gray diamonds indicate the regional estimates of sea-surface temperatures (for sources, see Table 1). All tags sensed light or air by or before they began to transmit at the end of each temperature record; arrows indicate the end of records and onset of transmissions for each tag. The gray shaded area at the top of this graph indicates the normal range of abdominal temperatures for healthy sea lions (Fig. 1).

decline in peak temperature is consistent with the rate observed in laboratory simulations $(n=15)$ of tag transfers to water: $0.88^{\circ} \mathrm{C} \mathrm{min}^{-1}$ (SD 0.14; Fig. 2C; Horning and Mellish, 2009). In all 11 cases, tags uplinked at the first opportunity after each had sensed ambient light, air, or both, indicating immediate tag extrusion at sea. This notion was confirmed by the locations of initial uplinks at sea. In all 11 events, the recorded postmortem temperatures coincided with regional SST estimates (Fig. 3; Table 1).

One type-III event was observed. This event yielded only a single complete data set with temperatures that

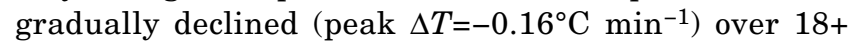
$\mathrm{h}$ to $4.51^{\circ} \mathrm{C}$, close to the regional SST of $3.98^{\circ} \mathrm{C}$ (Fig. 4 ; Table 1). Transmissions began $16 \mathrm{~d}$ post mortem. The algor mortis model yielded a mass estimate of only 24 $\mathrm{kg}$, significantly below the mass of the animal at release (146 kg; model output shown in Fig. 4) and the estimated mass at the age of death $(158 \mathrm{~kg})$, and indicating partial dismemberment (Horning and Mellish, 2009).

Of the remaining 3 events, 2 events fell into a typeIV scenario. In the first event (TJ52), only a single transmitter uplinked. This tag recorded a precipitous temperature drop (peak $\Delta T=-0.98^{\circ} \mathrm{C} \min ^{-1}$ ) to $5.53^{\circ} \mathrm{C}$, but the tag did not sense light or air and did not transmit until $11 \mathrm{~d}$ post mortem (Table 1; Fig. 5). Multiple uplink temperatures of $11.98^{\circ} \mathrm{C}$ corresponded to the regional SST estimate of $11.90^{\circ} \mathrm{C}$, more than double the recorded postmortem temperatures.

In the second event (TJ64), both tags sensed precipitous drops (peak $\Delta T=-0.93^{\circ} \mathrm{C} \mathrm{min}^{-1}$ ) to a temperature 


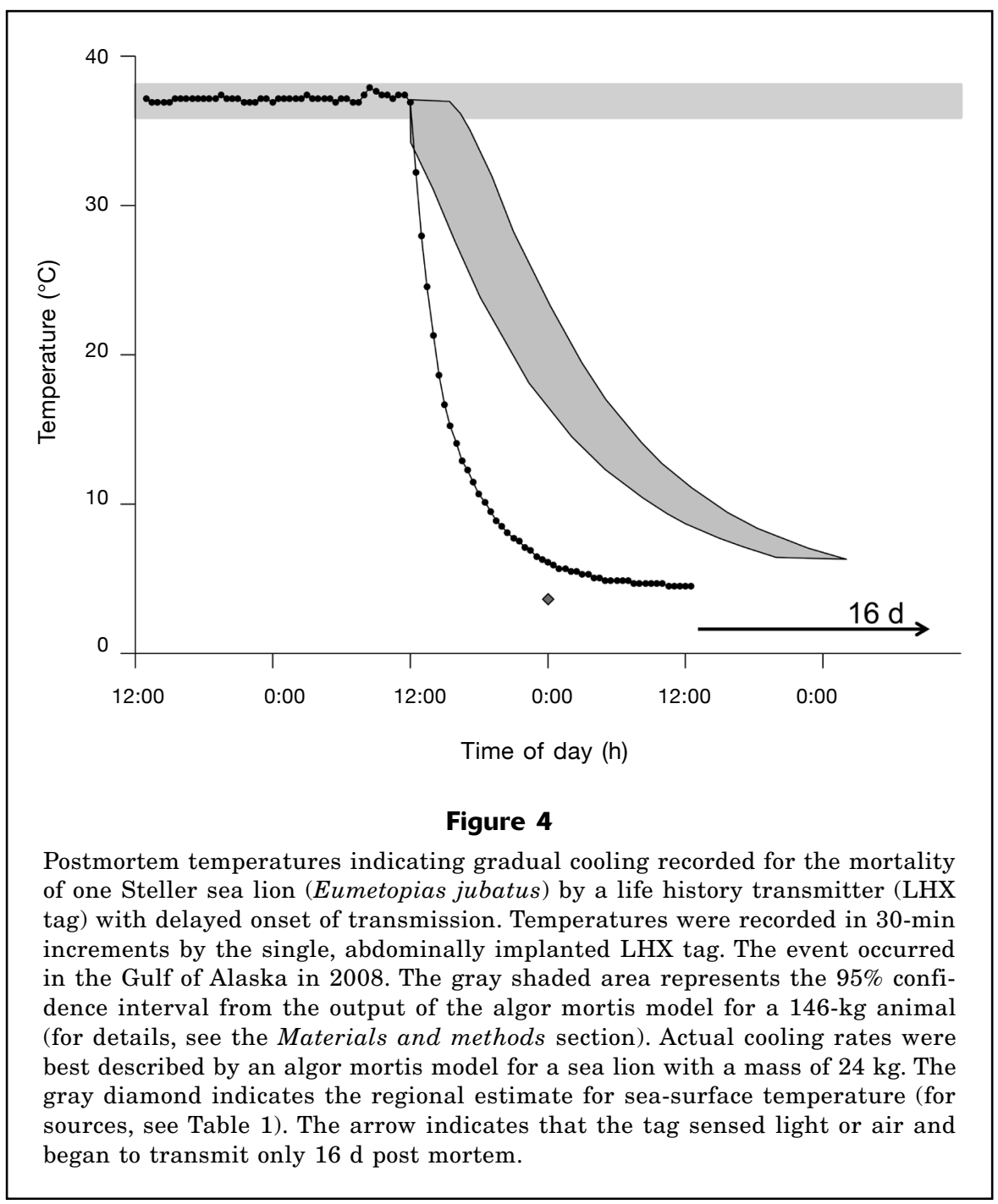

of $7.55^{\circ} \mathrm{C}$ but did not sense light or air, and they did not commence transmissions until 5 and $9 \mathrm{~d}$ post mortem, respectively (Table 1; Fig. 5). The regional SST estimate of $4.97^{\circ} \mathrm{C}$ was more than $2^{\circ} \mathrm{C}$ below recorded postmortem temperatures, and it was closely matched by uplink temperatures of $5.22^{\circ} \mathrm{C}$ from 1 tag $(5 \mathrm{~d}$ post mortem). The second tag was beached by the time of the first successful uplink (9 d post mortem) and reported air temperatures near freezing.

The 2 tags from the remaining event (TJ63) recorded disparate details that corresponded with type-I and -IV scenarios (Fig. 5). One tag (type I) recorded precipitous temperature drops (peak $\Delta T:-0.94^{\circ} \mathrm{C} \mathrm{min}^{-1}$ ) to $5.20^{\circ} \mathrm{C}$, close to the regional SST estimate of $5.07^{\circ} \mathrm{C}$ (Table 1). This tag began making transmissions at the first opportunity after sensing air and light, reporting uplink temperatures of $5.73^{\circ} \mathrm{C}$. The second tag (type IV), however, recorded a precipitous drop (peak $\Delta T$ : $-0.90^{\circ} \mathrm{C} \mathrm{min}-1$ ) to $7.02^{\circ} \mathrm{C}$. It started transmissions only $6 \mathrm{~d}$ later, after sensing light or air, and reported tem- peratures of $5.13^{\circ} \mathrm{C}$, a level close to the regional SST estimate of $4.73^{\circ} \mathrm{C}$ (Table 1 ).

Pairs of LHX tags without disparate fates (as indicated by light or air data) reported consistent postmortem temperatures: the mean difference within pairs $(n=11)$ was $0.15^{\circ} \mathrm{C}$ (SD 0.13), the maximum difference was $0.51^{\circ} \mathrm{C}$. Temperatures uplinked by tags free-floating at the sea surface also were consistent with regional SST estimates, with a mean difference within pairs $(n=16)$ of $0.32^{\circ} \mathrm{C}$ (SD 0.31). The mean difference between postmortem temperatures and SSTs for tags without delayed transmissions $(n=23)$ was $0.24^{\circ} \mathrm{C}(\mathrm{SD} 0.21)$. However, the average (absolute) difference between regional SST estimates and postmortem temperatures reported by 4 tags that showed both precipitous temperature drops and delayed transmissions was considerably higher at $3.29^{\circ} \mathrm{C}$ (range: $1.95-6.05^{\circ} \mathrm{C}$; Fig. 5). Each of these 4 tags also recorded postmortem temperatures that were extremely constant, with maximum temperature fluctuations of $0.0^{\circ} \mathrm{C}, 0.2^{\circ} \mathrm{C}, 0.0^{\circ} \mathrm{C}$, and $0.0^{\circ} \mathrm{C}$ over a period of 


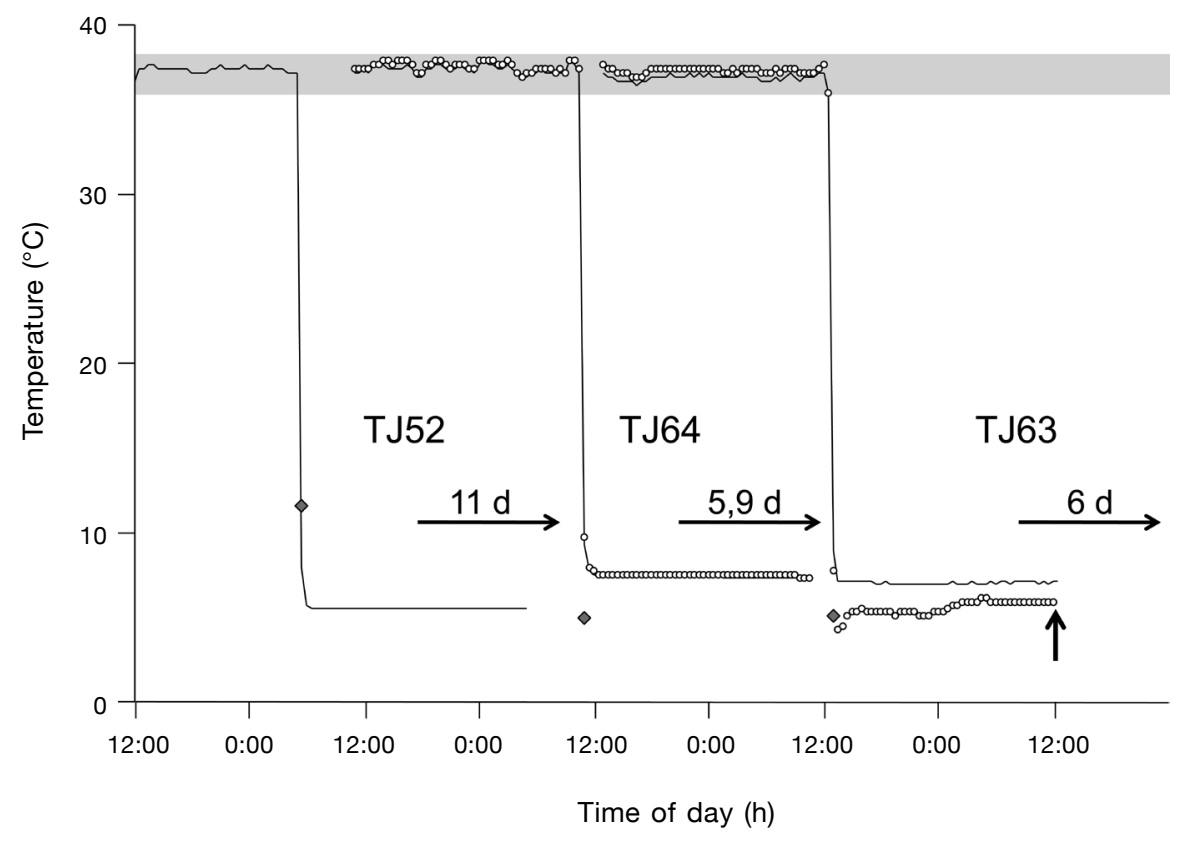

Figure 5

Postmortem temperatures indicating rapid cooling recorded for 3 mortalities of Steller sea lions (Eumetopias jubatus) and subsequently transmitted by life history transmitters (LHX tags) with delayed onset of transmissions. The 3 events occurred in the Gulf of Alaska in 2011. Temperatures were recorded by 5 tags in 30-min increments and subsequently transmitted through the Argos satellite system. Data were received from only 1 LHX tag for animal number TJ52. The left horizontal arrow indicates that this tag sensed light or air and began transmissions 11 days post mortem. Data were received from 2 LHX tags for animal TJ64 (line, circles). The middle horizontal arrow indicates that these tags sensed air or light and began to transmit 5 and $9 \mathrm{~d}$ post mortem. The right horizontal arrow indicates that one LHX tag from animal TJ63 (line) sensed light or air and began transmissions $6 \mathrm{~d}$ post mortem. The vertical arrow indicates when the second tag from the sea lion TJ63 (circles) began to transmit after sensing light or air. Gray diamonds indicate the regional estimates of sea-surface temperatures (for sources, see Table 1). The gray shaded area at the top of this graph indicates the normal range of abdominal temperatures for healthy sea lions (Fig. 1).

$24 \mathrm{~h}$ post mortem. Conversely, 5 tags without delayed transmissions from hosts that died close to noon and, therefore, also provided $24 \mathrm{~h}$ of postmortem temperatures recorded maximum fluctuations of $0.82^{\circ} \mathrm{C}, 1.43^{\circ} \mathrm{C}$, $1.83^{\circ} \mathrm{C}, 2.2^{\circ} \mathrm{C}$, and $2.4^{\circ} \mathrm{C}$ (Table 1 ).

\section{Discussion}

We previously reported that survival rates based on data from LHX tags for juveniles of ages 14-60 months in our study were indistinguishable from control values from a separate study based on resightings of individuals that had been hot-iron branded (Horning and Mellish, 2012; see Materials and methods section). Our probability for event detection was very high at $98.4 \%$, indicating that, most likely, no events went undetected. This high level of probability supports the hypothesis that LHX tags or surgeries do not affect postrelease survival to 60 months in implanted juvenile Steller sea lions. All 15 detected mortality events with data were classified as death by predation on the basis of precipitous temperature declines (14 events) or the very low mass indicated by the algor mortis model (1 event). In combination, these findings support the notion that none of the events reported here were caused by implanted tags or tagging procedures; after all, it would seem highly improbable that LHX tags could increase the susceptibility of sea lions to predation without a concurrent decrease in long-term survival rates below control values.

Theoretically, the observed patterns of rapid drops in temperature could be associated with direct extrusion of a tag by a live host animal. Noncatastrophic extrusion (i.e., percutaneous) is a slow process that should result in substantially different times for the 
temperature drops recorded by the 2 implanted tags. No such differences were recorded in this study. Rapid, catastrophic extrusions (i.e., endogastric) are almost certainly lethal and would result in lower survival rates compared with the rates of control groups. We, therefore, deem direct extrusion as extremely unlikely.

It is also possible that rapid temperature drops resulted from tags liberated by scavengers that fed on a carcass within 30-60 min post mortem. Scavenging after a longer time would have revealed at least initial changes of cooling conforming to a type-II scenario (Fig. 2). Many processes that lead to death are associated with the reduced ability of marine mammals to thermoregulate (Dierauf and Gulland, 2001; Rosen et al., 2007; Stoskopf, 2005). Inflammation and infection often lead to pyrexia (fever). In extreme cases of septicemia, temperatures may even continue to rise post mortem. Hypoglycemia, starvation and emaciation, congestive cardiac failure, hemorrhage, and shock are all associated with a reduced body-core temperature. Furthermore, many injured or diseased pinnipeds have a tendency to come ashore and die there (Dierauf and Gulland, 2001), although this behavior may not apply to highly pelagic species, such as elephant seals. None of the observed events were associated with any signs of compromised health, such as pyrexia or hypothermia, and all events occurred at sea. Death from drowning (following entanglement) should lead to a type-III scenario that involves slightly accelerated, internal cooling by inhaled cold water, although not to the level exhibited in Figure 3 (in marine mammals, total lung capacity [in liters] is typically $<10 \%$ of body mass [in kilograms]; Kooyman [1989]).

This evaluation of various possible cooling rates and antemortem temperatures indicates that, at onset of the rapid temperature drops shown in Figure 4 and 5 , the animals were alive and healthy and that death likely coincided with rather than preceded releases of LHX tags. Therefore, although scavenging shortly after death could not be categorically excluded at this point, we found no evidence of nontraumatic death at sea and deem such an event unlikely. Predation is the most likely and consistent interpretation for all 15 events, which fit type-I, -III, or -IV scenarios, discussed here.

Tags from 11 type-I events quickly sensed light or air and did not have delayed transmissions. These tags reported postmortem temperatures that corresponded with regional SST estimates. These events may have happened at or near the sea surface, where tags were exposed quickly to ambient light while their antennas floated above water. Free-floating LHX tags ascended at a mean rate of $1.3 \mathrm{~m} \mathrm{~s}^{-1}$ (standard error of mean [SE] 0.05) during runs $(n=10)$ simulated in laboratory trials (senior author, unpubl. data). Even tags liberated at a depth of $500 \mathrm{~m}$, beyond the $300 \mathrm{~m}$ reported as the deepest dive depth for juvenile Steller sea lions (Mellish et al., 2007), still would reach the surface within $10 \mathrm{~min}$, and, once there, they would record temperatures corresponding to the SST and the air surround- ing their floating antennas, and ambient light levels would trigger transmissions. Therefore, no inferences can be made from these 11 type-I events on the species of the predator.

One type-III event yielded a gradual temperature decline from 1 tag with delayed sensing of light and air. The tag cooled to a temperature of $4.51^{\circ} \mathrm{C}$, a level above the regional SST estimate of $3.7^{\circ} \mathrm{C}$ but similar to values for temperatures at a depth of approximately 50 $\mathrm{m}$. This temperature pattern could be the result of the sinking of the LHX tag after dismemberment of the animal, with a portion of sea lion tissue surrounding the tag, to a depth where the slightly warmer water temperature was recorded. However, LHX tags are coated with a material designed to prevent connective tissue growth and encapsulation or adhesion to the omentum in the abdominal gut cavity (Horning and Hill, 2005). Temperature drops from all other tags indicated immediate and complete separation from all tissue, and all 9 tags that were physically recovered-including the tag from this type-III event-had no signs of connective tissue or adhesion. It is difficult to imagine that a 24$\mathrm{kg}$ portion of abdominal tissue could remain after dismemberment and could contain a tag for an extended period of time without the tag being released. It seems more plausible that this LHX tag and some sea lion tissue were ingested together by a cold-bodied predator, resulting in gradual cooling in darkness.

In the 3 remaining events, 4 tags with precipitous drops and delayed onset of transmissions recorded temperatures different from SSTs but similar to estimates for temperatures at depths between $50 \mathrm{~m}$ (TJ63, TJ64) and $200 \mathrm{~m}$ (TJ52) for $24 \mathrm{~h}$ post mortem (Table 1; Fig. 5). These tags detected light or air only 5-11 d post mortem, at which time uplink temperatures corresponded with regional SST estimates. The combination of the absence of light or air and of extended recordings of deepwater temperatures indicates that these tags remained in the dark while surrounded by a cold, wet medium after their abrupt removal from the bodies of their hosts. In 1 event, only 1 of 2 tags recorded deepwater temperatures while remaining in the dark, but the other tag recorded postmortem temperatures that matched regional SST estimates and uplinked data immediately after sensing light and air (Fig. 2). The postmortem temperatures recorded by each of the 4 tags with delayed uplinks essentially were constant, in comparison with data from tags that floated at the surface and recorded temperature fluctuations between $0.82^{\circ} \mathrm{C}$ and $2.40^{\circ} \mathrm{C}$ over a 24 -h period.

The most parsimonious explanation for our data is that the 4 tags with precipitous temperature drops and delayed onset of transmissions were ingested after an attack by a cold-bodied predator. Tag ingestion simultaneously explains absence of air and light, delayed onset of transmissions, and constant postmortem temperatures distinct from SSTs. Three poikilotherm species have been reported as potential predators of Steller sea lions (Loughlin and York, 2000): the white shark, the 
salmon shark, and the Pacific sleeper shark. All 3 species have been documented feeding within Alaskan waters and the Bering Sea (Compagno, 1984; Benz et al., 2004; Martin, 2005). However, lamnid sharks, including the salmon shark (Smith and Rhodes, 1983; Anderson and Goldman, 2001; Goldman et al., 2004; Bernal et al., 2005) and the white shark (McCosker, 1987; Goldman, 1997), have been shown to maintain body-core and stomach temperatures consistently $6-15^{\circ} \mathrm{C}$ above ambient temperatures even in subarctic regions with SSTs below $5^{\circ} \mathrm{C}$. Therefore, the Pacific sleeper shark emerges as the only potential predator of Steller sea lions in the North Pacific and Bering Sea region whose body-core temperatures likely remain at mid-water values.

The postmortem ingestion by Pacific sleeper sharks of tags released through the attack of a different predator is another possible interpretation. However, a delayed secondary ingestion at the surface still would expose LHX tags to SSTs and ambient light, and the probability of a simultaneous encounter of a sea lion and 2 distinct predator species at depth would be very low, in part because it would expose Pacific sleeper sharks to predation risk (Ford et al., 2011).

The Pacific sleeper shark is found in the North Pacific and the Bering Sea. Pacific sleeper sharks have been documented in shallow coastal waters and even in estuarine waters in the arctic regions of the North $\mathrm{Pa}$ cific and at oceanic depths $(>2700 \mathrm{~m})$ in temperate latitudes (Compagno, 1984; Ebert et al., 1987; Hulbert et al., 2006; Sigler et al., 2006; Yano et al., 2007). Although the very large (up to $7 \mathrm{~m}$ in total length [TL]) Greenland shark (Somniosus microcephalus) may have the northernmost range documented for species of this genus, the range of the Pacific sleeper shark extends into the Bering Sea and past the Arctic Circle (Bright, 1959; Orlov, 1999; Orlov and Moiseev, 1998, 1999; Benz et al., 2004; Hulbert et al., 2006; Courtney and Sigler, 2007).

Pacific sleeper sharks have been documented to reach adult lengths up to $4.4 \mathrm{~m}$ TL (Compagno, 1984; Mecklenburg et al., 2002; Yano et al., 2007), but estimates from historic and contemporary photographic and video recordings indicate that they may reach lengths in excess of $7 \mathrm{~m}$ TL (Hart, 1973; Compagno, 1984). The estimated TL at sexual maturity is $3.7 \mathrm{~m}$ for females and $4.0 \mathrm{~m}$ for males (on the basis of the length of the few sexually mature individuals ever caught: Ebert et al., 1987; Courtney and Sigler, 2007; Yano et al., 2007). To date, only 5 mature females have been reported from bycatch ${ }^{2}$. Pacific sleeper sharks are slow growing and long-lived (Ebert et al., 1987), supporting the notion that mature adults should reach sizes well beyond 4-5 m TL.

\footnotetext{
2 Tribuzio, C. A., K. Echave, C. Rodgveller, J. Heifetz, and K. J. Goldman. 2010. Assessment of the sharks in the Bering Sea and Aleutian Islands. In stock assessment and fishery evaluation report for the groundfish resources of the Bering Sea/Aleutian Islands regions, p. 1451-1500. [Available from North Pacific Fishery Management Council, 605 West 4th Ave., Suite 306, Anchorage, AK 99501.]
}

Pacific sleeper sharks have a broad range of diet that includes benthic and mid-water crustaceans, cephalopods, salmonids, gadids, flatfish, and marine mammals (Bright, 1959; Compagno, 1984; Yang and Page, 1998; Orlov, 1999; Orlov and Moiseev, 1998, 1999; Sigler et al., 2006; Yano et al., 2007). Genetically identified stomach contents have included cetaceans and phocids; however, a histological analysis of ingested tissue indicated scavenging rather than live captures in the case of all cetacean and some phocid samples, and the evidence was inconclusive for some freshly ingested phocid tissue (Sigler et al., 2006).

Pacific sleeper sharks may appear to be improbable predators of fast-swimming and agile prey as large as juvenile Steller sea lions, especially given the adaptation of the functional morphology of their feeding apparatus toward suction feeding. Evidence shows that Pacific sleeper sharks have removed large circular sections, cookie-cutter style, from whale carcasses (Barrett-Lennard et al., 2011). Such an injury, if inflicted on the lower abdominal area (between diaphragm and pelvic girdle) of large juvenile sea lions, could result in LHX tag ingestion and would be lethal if it occurred ante mortem.

Several studies of shark predation on marine mammals (Arnold, 1972; Cockroft et al., 1989; Heithaus, 2001; Bertilsson-Friedman, 2006) have indicated that predation attempts often involve approaches from below and the rear and may focus on abdominal areas. However, the attack behavior of the Pacific sleeper shark has not been studied. Pacific sleeper sharks do appear capable of preying on fast-swimming salmonids and scombrids (Ebert et al., 1987; Sigler et al., 2006). Larger and older Greenland sharks have been shown to prey on live pinnipeds (Fisk et al., 2002; Leclerc et al., 2012), although such events may be ambush attacks on seals sleeping at the ocean surface (Watanabe et al., 2012). Southern sleeper sharks (Somniosus antarcticus) have been reported to attack live southern elephant seals (Mirounga leonina) (Van Den Hoff and Morrice, 2008).

Because of the potential habitat overlap, the role of the Pacific sleeper shark as a potential predator of Steller sea lions was investigated. A modeling exercise by Frid et al. (2009) revealed sea lion dive behavior as avoidance of predation risk from transient killer whales and Pacific sleeper sharks. The model output was supported by telemetered data of sea lion dive behavior in Prince William Sound. Yet, no sea lion remains were identified in the stomachs of 198 Pacific sleeper sharks caught by long-lining near sea lion rookeries (Sigler et al., 2006). However, these 198 sharks were collected during 2 sampling periods in May and August and within 1-12 km of sea lion rookeries or haulouts (Sigler et al., 2006).

Only 3 of the 15 predation events that were detected in our study occurred within the 4-month period of May-August (Table 1), and none of these 3 events occurred within $20 \mathrm{~km}$ of rookeries or haulouts. Fur- 
thermore, the absence of sea lion remains could be explained by the comparably small size (1.3-2.8 m TL) of the sharks sampled, if smaller sharks are less likely to attack larger and faster prey items. All sampled animals were probably immature (Courtney and Sigler, 2007). This size bias could be driven by the possible absence of larger sharks in the region (Hulbert et al., 2006) or by the possible size bias of long-lining toward younger, smaller individuals (for remarks on landing and sampling likelihood for long-line gear, see Orlov and Moiseev, 1999; Yano et al., 2007; Courtney and Sigler, 2007). Courtney and Foy (2012) reported an increase in trophic position with TL in Pacific sleeper sharks. They suggested that the diet of the Pacific sleeper shark probably also varies by time and location of capture and in response to prey availability. Therefore, given the evidence of ontogenetic, seasonal, and geographic diet shifts in many shark species, including the Greenland shark, southern sleeper shark, and Pacific sleeper shark (Orlov and Moiseev, 1999; Fisk et al., 2002; Yano et al., 2007; Courtney and Foy, 2012), the absence of sea lion tissue in the sampled sharks is, perhaps, not surprising and does not contradict our indirect evidence of predation on Steller sea lions.

\section{Conclusions}

Of all observed events of predation on juvenile Steller sea lions, at least 3 and likely 4 in 15-or approximately $27 \%$ - could be attributed to Pacific sleeper sharks. Although these observations do not constitute proof of attacks on live Steller sea lions by Pacific sleeper sharks, our data indicate that Pacific sleeper sharks need to be considered as a possible source of mortality of juvenile Steller sea lions in the region of the Gulf of Alaska and Prince William Sound.

\section{Acknowledgments}

We appreciate the assistance provided by the dive capture and husbandry teams of the Alaska Sea Life Center. Implant surgeries were conducted by M. Haulena, P. Tuomi, C. Goertz, and R. Berngartt. This study was supported by grants from the North Pacific Marine Research Program (00-0029), U. S. Department of Commerce Steller Sea Lion Research Initiative (NA17FX1429), North Pacific Research Board (F4011), and Pollock Conservation Cooperative Research Center (01-0047 \& G5498) and by the Alaska Sea Life Center with the use of U. S. Department of Commerce funds. These funding organizations had no role in the design of this study, data collection and analysis, the decision to publish, or preparation of this manuscript.

\section{Literature cited}

Anderson, S. D., and K. J. Goldman.

2001. Temperature measurements from salmon sharks, Lamna ditropis, in Alaskan waters. Copeia: 2001:794-796.

Arnold, P. W.

1972. Predation on harbour porpoise, Phocoena phococena, by a white shark, Carcharodon carcharias. J. Fish. Res. Board Can. 29:1213-1214.

Barrett-Lennard, L. G., C. O. Matkin, J. W. Durban, E. L. Saulitis, and D. Ellifrit.

2011. Predation on gray whales and prolonged feeding on submerged carcasses by transient killer whales at Unimak Island, Alaska. Mar. Ecol. Prog. Ser. 421:229-241.

Benz, G. W., R. Hocking, A. Kowunna, Sr., S. A. Bullard, and J. C. George.

2004. A second species of Arctic shark: Pacific sleeper shark Somniosus pacificus from Point Hope, Alaska. Polar Biol. 27:250-252.

Bernal, D., J. M. Donley, R. E. Shadwick, and D. A. Syme.

2005. Mammal-like muscles power swimming in a coldwater shark. Nature 437:1349-1352.

Bertilsson-Friedman, P.

2006. Distribution and frequencies of shark-inflicted injuries to the endangered Hawaiian monk seal (Monachus schauinslandi). J. Zool. 268:361-368.

Bright, D. B.

1959. The occurrence and food of the sleeper shark, Somniosus pacificus, in a central Alaska bay. Copeia 1959:76-77.

Cockroft, V. G., G. Cliff, and G. J. B. Ross.

1989. Shark predation on Indian Ocean bottlenose dolphins (Tursiops truncatus) off Natal, South Africa. S. Afr. J. Zool. 24:305-310.

Compagno, L. J. V.

1984. FAO species catalogue, vol. 4. Sharks of the world: An annotated and illustrated catalogue of shark species known to date. Part 1-Hexanchiformes to Lamniformes. FAO Fish. Synop. 125, 249 p. FAO, Rome.

Costa, D. P., P. W. Robinson, J. P. Y. Arnould, A-L. Harrison, S. E. Simmons, J. L. Hassrick, A. J. Hoskins, S. P. Kirkman, H. Oosthuizen, S. Villegas-Amtmann, and D. E. Crocker.

2010. Accuracy of ARGOS locations of pinnipeds atsea estimated using Fastloc GPS. PLoS ONE 5(1):e8677. doi:10.1371/journal.pone.0008677

Courtney, D. L., and R. Foy.

2012. Pacific sleeper shark Somniosus pacificus trophic ecology in the eastern North Pacific Ocean inferred from nitrogen and carbon stable-isotope ratios and diet. J. Fish Biol. 80:1508-1545.

Courtney, D. L., and M. F. Sigler.

2007. Trends in area-weighted CPUE of Pacific sleeper sharks Somniosus pacificus in the northeast $\mathrm{Pa}-$ cific Ocean determined from sablefish longline surveys. Alaska Fish. Res. Bull. 12:292-316.

Dierauf, L. A., and F. M. D. Gulland.

2001. CRC Handbook of Marine Mammal Medicine, $2^{\text {nd }}$ ed., 1120 p. CRC Press, Boca Raton, FL.

Ebert, D. A., L. J. V. Compagno, and L. J. Natanson.

1987. Biological notes on the Pacific sleeper shark, Somniosus pacificus (Chondrichthyes: Squalidae). Calif. Fish Game 73:117-123. 
Fisher, R. A.

1922. On the interpretation of $\chi^{2}$ from contingency tables, and the calculation of P. J. R. Stat. Soc. 85:87-94.

Fisk, A. T., S. A. Tittlemier, J. L. Pranschke, and R. J. Norstrom. 2002. Using anthropogenic contaminants and stable isotopes to assess the feeding ecology of Greenland sharks. Ecology 83:2162-2172.

Ford, J. K. B., G. M. Ellis, L. G. Barrett-Lennard, A. B. Morton, R. S. Palm, and K. C. Balcomb III.

1998. Dietary specialization in two sympatric populations of killer whales (Orcinus orca) in coastal British Columbia and adjacent waters. Can. J. Zool. 76:1456-1471.

Ford, J. K. B., G. M. Ellis, C. O. Matkin, M. H. Wetklo, L. G.

Barrett-Lennard, and R. E. Withler.

2011. Shark predation and tooth wear in a population of northeastern Pacific killer whales. Aquat. Biol. 11:213-224.

Frid, A., J. Burns, G. G. Baker, and R. E. Thorne.

2009. Predicting synergistic effects of resources and predators on foraging decisions by juvenile Steller sea lions. Oecologia 158:775-786.

Fritz, L., K. Sweeney, D. Johnson, M. Lynn, T. Gelatt, and J. Gilpatrick.

2013. Aerial and ship-based surveys of Steller sea lions (Eumetopias jubatus) conducted in Alaska in June-July 2008 through 2012, and an update on the status and trend of the western distinct population segment in Alaska. NOAA Tech. Memo. NMFS-AFSC-251, 91 p.

Gay, S. M., III, and S. L. Vaughan.

2001. Seasonal hydrography and tidal currents of bays and fjords in Prince William Sound, Alaska. Fish. Oceanogr. 10 (suppl. 1):159-193.

Goldman, K. J.

1997. Regulation of body temperature in the white shark, Carcharodon carcharias. J. Comp. Physiol., B 167:423-429.

Goldman, K. J., S. D. Anderson, R. J. Latour, and J. A. Musick. 2004. Homeothermy in adult salmon sharks, Lamna ditropis. Environ. Biol. Fishes 71:403-411.

Hart, J. L.

1973. Pacific fishes of Canada. Fish. Res. Board Can. Bull. 180, $740 \mathrm{p}$.

Heise, K., L. G. Barrett-Lennard, E. Saulitis, C. Matkin, and D. Bain.

2003. Examining the evidence for killer whale predation on Steller sea lions in British Columbia and Alaska. Aquat. Mamm. 29:325-334.

Heithaus, M. R.

2001. Shark attacks on bottlenose dolphins (Tursiops truncatus) in Shark Bay, Western Australia: attack rate, bite scar frequencies, and attack seasonality. Mar. Mamm. Sci. 17:526-539.

Henssge, C.

1995. Temperature-based methods II. In The estimation of the time since death in the early postmortem period (C. Henssge, B. Knight, T. Krompecher, B. Medea, and L. Nokes, eds.), p. 46-105. Edward Arnold, London.

Holmes, E. E., L. W. Fritz, A. E. York, and K. Sweeney.

2007. Age-structured modeling reveals long-term declines in the natality of western Steller sea lions. Ecol. Appl. 17:2214-2232.
Horning, M., and R. D. Hill.

2005. Designing an archival satellite transmitter for life-long deployments on oceanic vertebrates: the Life History Transmitter. IEEE J. Ocean. Eng. 30:807-817.

Horning, M., M. Haulena, P. A. Tuomi, and J. E. Mellish.

2008. Intraperitoneal implantation of life-long telemetry transmitters in otariids. BMC Vet. Res. 2008, 4:51. doi:10.1186/1746-6148-4-51

Horning, M., and J. E. Mellish.

2009. Spatially explicit detection of predation on individual pinnipeds from implanted post-mortem satellite data transmitters. Endang. Species Res. 10:135-143.

2012. Predation on an upper trophic marine predator, the Steller sea lion: evaluating high juvenile mortality in a density dependent conceptual framework. PLoS ONE 7(1):e30173. doi:10.1371/journal.pone.0030173

Hulbert, L. B., M. F. Sigler, and C. R. Lunsford.

2006. Depth and movement behavior of the Pacific sleeper shark in the north-east Pacific Ocean. J. Fish Biol. 69:406-425.

Kooyman, G. L.

1989. Diverse divers: physiology and behavior, 200 p. Springer-Verlag, Berlin.

Leclerc, L. E., C. Lydersen, T. Haug, L. Bachmann, A. T. Fisk, and K. M. Kovacs.

2012. A missing piece in the Arctic food web puzzle? Stomach contents of Greenland sharks sampled in Svalbard, Norway. Polar Biol. 35:1197-1208.

Loughlin, T. R., and A. E. York.

2000. An accounting of the sources of Steller sea lion, Eumetopias jubatus, mortality. Mar. Fish. Rev. 62:40-45.

Maniscalco, J. M., Matkin, C. O., Maldini, D., Calkins, D. G., and S. Atkinson.

2007. Assessing killer whale predation on Steller sea lions from field observations in Kenai Fjords, Alaska. Mar. Mamm. Sci. 23:306-321.

Marshall, T. K., and F. E. Hoare.

1962. I. Estimating the time of death. The rectal cooling after death and its mathematical expression. II. The use of the cooling formula in the study of post-mortem body cooling. III. The use of the body temperature in estimating the time of death. J. Forensic Sci. 7:56-81, 189-210, 211-21.

Martin, R. A.

2005. Northerly distribution of white sharks, Carcharodon carcharias, in the eastern Pacific and relation to ENSO events. Mar. Fish. Rev. 66:16-26.

McCosker, J. E.

1987. The white shark, Carcharodon carcharias, has a warm stomach. Copeia 1987:195-197.

Mecklenburg, C. W., T. A. Anthony, and L. K. Thorsteinson. 2002. Fishes of Alaska, 1116 p. Am. Fish. Soc., Bethesda, MD.

Mellish, J. E., D. G. Calkins, D. R. Christen, M. Horning, L. D. Rea, and S. K. Atkinson.

2006. Temporary captivity as a research tool: comprehensive study of wild pinnipeds under controlled conditions. Aquat. Mamm. 32:58-65.

Mellish, J., J. Thomton, and M. Horning.

2007. Physiological and behavioral response to intraabdominal transmitter implantation in Steller sea lions. J. Exp. Mar. Biol. Ecol. 351:283-293. 
National Research Council.

2003. The decline of the Steller sea lions in Alaskan waters: untangling food webs and fishing nets, $216 \mathrm{p}$. National Academy Press, Washington, D.C.

Orlov, A. M.

1999. Capture of especially large sleeper shark Somniosus pacificus (Squalidae) with some notes on its ecology in northwestern Pacific. Vopr. Ikhtiol. 39:558563. [In Russian. English translation in J. Ichthyol. 39:548-553.].

Orlov, A. M., and S. I. Moiseev.

1998. New data on the biology of the Pacific Sleeper Shark Somniosus pacificus (Squalidae) in the Northwestern Pacific Ocean. In Fish performance studies: symposium proceedings of the International Congress on the Biology of Fish; Baltimore, 27-30 July 1998 (D. MacKinlay, K. Howard., and J. Cech Jr., eds.), p. 177186. Am. Fish. Soc., Bethesda MD.

1999. Some biological features of Pacific sleeper shark, Somniosus pacificus (Bigelow and Schroeder 1944) (Squalidae) in the northwestern Pacific Ocean. Oceanol. Stud. 28:3-16.

Petrauskas, L., S. Atkinson, F. Gulland, J. Mellish, and M. Horning.

2008. Monitoring glucocorticoid response to rehabilitation and research procedures in California and Steller sea lions. J. Exp. Zool. A Ecol. Gen. Physiol. 309:73-82.

Rosen, D. A. S., A. J. Winship, and L. A. Hoopes.

2007. Thermal and digestive constraints to foraging behavior in marine mammals. Philos. Trans. R. Soc. Lond., Ser. B: Biol. Sci. 362:2151-2168.

Sasaki, H., S. Saitoh, and M. Kishino.

2001. Bio-optical properties of seawater in the Western subarctic Gyre and Alaskan Gyre in the subarctic North Pacific and southern Bering Sea during the summer of 1997. J. Oceanogr. 57:275-284.

Sigler, M. F., L. B. Hulbert, C. R. Lunsford, N. H. Thompson, K. Burek, G. O'Corry-Crowe, and A. C. Hirons.

2006. Diet of Pacific sleeper shark, a potential Steller sea lion predator, in the north-east Pacific Ocean. J. Fish Biol. 69:392-405.

Smith, R. L., and D. Rhodes. 1983. Body temperature of the salmon shark, Lamna ditropis. J. Mar. Biol. Assoc. U.K. 63:243-244.

Soma, M., and M. Tsutsumi.

1986. Biological telemetry utilizing the Argos system. Mesogee 46:87-92.

Stoskopf, M. K.

2005. Bacterial diseases of marine mammals. In The
Merck veterinary manual, $9^{\text {th }}$ ed. (C. M. Kahn and S. Line, eds.), p. 1347-1361. Merck Sharp \& Dohme Corp., Whitehouse Station, NJ.

Thomton, J. D., J. E. Mellish, D. R. Hennen, and M. Horning. 2008. Juvenile Steller sea lion foraging behavior following temporary captivity. Endang. Species Res. 4:195-203.

Trites, A. W., A. J. Miller, H. D. G. Maschner, M. A. Alexander, S. J. Bograd, J. A. Calder, A. Capotondi, K. O. Coyle, E. D. Lorenzo, B. P. Finney, E. J. Gregr, C. E. Grosch, S. R. Hare, G. L. Hunt Jr., J. Jahnke, N. B. Kachel, H.-J. Kim, C. Ladd, N. J. Mantua, C. Marzban, W. Maslowski, R. Mendelssohn, D. J. Neilson, S. R. Okkonen, J. E. Overland, K. L. ReedyMaschner, T. C. Royer, F. B. Schwing, J. X. L. Wang, and A. J. Winship.

2007. Bottom-up forcing and the decline of Steller sea lions (Eumetopias jubatus) in Alaska: assessing the ocean climate hypothesis. Fish. Oceanogr. 16:46-67.

Van Den Hoff, J., and M. G. Morrice.

2008. Sleeper shark (Somniosus antarcticus) and other bite wounds observed on southern elephant seals (Mirounga leonina) at Maquarie Island. Mar. Mamm. Sci. 24:239-247.

Walker, K. A., M. Horning, J. E. Mellish, and D. M. Weary.

2009. Behavioural responses of juvenile Steller sea lions to abdominal surgery: Developing an assessment of postoperative pain. Appl. Anim. Behav. Sci. 120:201-207.

Watanabe, Y. Y., C. Lydersen, A. T. Fisk, and K. M. Kovacs.

2012. The slowest fish: Swim speed and tail-beat frequency of Greenland sharks. J. Exp. Mar. Biol. Ecol. 426-427:5-11.

Whittow, G. C.

1987. Thermoregulatory adaptations in marine mammals: interacting effects of exercise and body mass. a review. Mar. Mamm. Sci. 3:220-241.

Williams, T. M., J. A. Estes, D. F. Doak, and A. M. Springer.

2004. Killer appetites: assessing the role of predators in ecological communities. Ecology 85:3373-3384.

Yang, M-S., and B. N. Page.

1998. Diet of Pacific sleeper shark, Somniosus pacificus, in the Gulf of Alaska. Fish. Bull. 97:406-409.

Yano, K., J. D. Stephens, and L. J. V. Compagno.

2007. Distribution, reproduction and feeding of the Greenland shark Somniosus (Somniosus) microcephalus, with notes on two other sleeper sharks, Somniosus (Somniosus) pacificus and Somniosus (Somniosus) antarcticus. J. Fish Biol. 70:374-390.

York, A. E.

1994. The population dynamics of northern sea lions, 1975-1985. Mar. Mam. Sci. 10:38-51. 